\title{
Outcome after neoadjuvant chemotherapy in elderly breast cancer patients - a pooled analysis of individual patient data from eight prospectively randomized controlled trials
}

\author{
Gabriel von Waldenfels ${ }^{1}$, Sibylle Loibl ${ }^{2}$, Jenny Furlanetto ${ }^{2}$, Anna Machleidt ${ }^{1}$, \\ Bianca Lederer ${ }^{2}$, Carsten Denkert ${ }^{3}$, Claus Hanusch ${ }^{4}$, Sherko Kümmel ${ }^{5}$, Gunter \\ von Minckwitz ${ }^{2}$, Andreas Schneeweiss ${ }^{6}$, Michael Untch ${ }^{7}$, Kerstin Rhiem ${ }^{8}$, Peter A. \\ Fasching $^{9}$ and Jens-Uwe Blohmer ${ }^{1}$ \\ ${ }^{1}$ Department of Gynecology and Breast Center, Charité University Hospital, Berlin, Germany \\ ${ }^{2}$ German Breast Group, Neu-Isenburg, Germany \\ ${ }^{3}$ Institute of Pathology, Charité University Hospital, Berlin, Germany \\ ${ }^{4}$ Rotkreuzklinikum, Munich, Germany \\ ${ }^{5}$ Breast Center, Kliniken Essen-Mitte, Essen, Germany \\ ${ }^{6}$ National Center for Tumor Diseases (NCT), Heidelberg, Germany \\ ${ }^{7}$ HELIOS Klinikum Berlin-Buch, Berlin, Germany \\ ${ }^{8}$ Center for Hereditary Breast and Ovarian Cancer, University Hospital Cologne, Köln, Germany \\ ${ }^{9}$ Department of Gynecology and Obstetrics, University Hospital Erlangen, Comprehensive Cancer Center Erlangen-EMN, \\ Friedrich-Alexander University Erlangen-Nuremberg, Erlangen, Germany
}

Correspondence to: Gabriel von Waldenfels, email: gabriel.von-waldenfels@charite.de

Keywords: elderly; pCR; neoadjuvant; breast; cancer survival; Gerotarget

Received: July 11,2017 Accepted: February 13, 2018 Epub: February 26, 2018 Published: March 16, 2018

Copyright: von Waldenfels et al. This is an open-access article distributed under the terms of the Creative Commons Attribution License 3.0 (CC BY 3.0), which permits unrestricted use, distribution, and reproduction in any medium, provided the original author and source are credited.

\section{ABSTRACT}

Introduction: Recent studies showed the high and independent impact of age $(<40$ years) on pathologic complete response ( $P C R$ ) and prognosis for patients undergoing neoadjuvant chemotherapy (NACT). Some physicians might not consider elderly patients ( $>65$ years) for NACT due to poor prognosis or higher toxicity. The aim of this analysis is to help selecting appropriately elderly women who would benefit from NACT. Secondly, survival parameters are investigated in several histological subgroups.

Methods: From 1998 to 2010, eight prospectively randomized German Breast Group (GBG) trials of anthracycline- and taxane-based NACT were performed and analyzed in this study.

Results: Compared to the overall average, elderly women had significant larger tumors and more overall lymph node involvement. Histologically, they had more $\mathbf{G 2}$ tumors, more estrogen-receptor positive tumors. PCR (YPTO ypNO) was strongly associated with age. The multivariable logistic regression analysis of clinical parameters showed that young age, clinical stage T4, invasive ductal cancer and poor differentiated breast cancer are predictive for high PCR. The multivariate analyses of molecular subgroups showed that age $>65$ years is a predictor of significant lower $\mathrm{PCR}$ in HER2- breast cancers. Nonetheless, HER2+ patients showed pCR rates as highand HR+/HER2+ even higher - pCR rates compared to younger patients.

Discussion: This study underlines the unfavorable impact of higher age on PCR, but it shows a realistic chance for PCR if NACT is applied - especially for HER2+ patients. Furthermore, elderly patients with non-TNBC showed a good prognosis (comparable to younger patients) regarding overall survival, even if they do not have PCR. 


\section{INTRODUCTION}

Age is considered a primary risk factor for the development of breast cancer. It is foreseen that, in the coming decades, approximately $20 \%$ of the population will be aged over 65 years and therefore, it is expected that the proportion of older women with breast cancer will grow considerably. Recent studies suggest that the median age for breast cancer diagnosis is approximately 60 years, and over $40 \%$ of all breast cancers diagnosed are in women aged 65 years or older [1]. In Germany a survey showed that more than half of all breast cancer patients are older than 65 years and more than a third are older than 70 years [2].

Management of older breast cancer patients is challenging. In general, chemotherapy is less often used in elderly [3], but the relative benefit from chemotherapy is independent from age [4]. The neoadjuvant use of chemotherapy seems even less of an option, partly due to the fact that it is less investigated in this population [3]. For some physicians neoadjuvant chemotherapy is only an option for elderly patients with inflammatory breast cancer or with locally advanced inoperable breast cancer. This might withhold the advantages of NACT, like prediction of prognosis and response adapted therapy, from elderly patients [5]. A recent analysis [6] of eight GBG-trials showed the high and independent impact of age on pathologic complete response (pCR) as well as the association of age with prognosis for patients undergoing NACT. Some other studies report as well that women $>65$ years have a lower pCR rate and detrimental prognosis as well as a higher toxicity compared to younger women $[7,8]$.

The first aim of this analysis is to help selecting appropriately elderly women who would benefit from NACT. Furthermore, we want to assess the effect of age on disease free survival (DFS), local-recurrence-free survival (LRFS), distant disease free survival (DDFS) and overall survival (OS) in the overall group, in the pCR group, in the non-pCR group and in biological subgroups defined by hormone receptor and HER2-status.

The hypothesis is that elderly breast cancer patients $(>65 \mathrm{y})$ with specific histological characteristics might have a high pCR rate or a good prognosis even without pCR after NACT compared to younger patients $(<40 \mathrm{y})$.

\section{MATERIALS AND METHODS}

\section{Patients}

From 1998 to 2010, eight prospectively randomized GBG-trials investigating NACT, GeparDuo [9], GeparTrio pilot [10] and main study [11], GeparQuattro [12], AGO 1 [13], Prepare [14], Techno [15], GeparQuinto trial [16] were performed. Patient data of these studies were combined in a metadatabase analysis. All trials had the approval of the responsible ethics committee. All patients gave written consent for their participation and data collection. The eight trials had comparable eligibility criteria [17]: All patients needed to have a primary breast cancer measurable either by ultrasound, palpation or mammography. Diagnosis was histologically confirmed by core biopsy. The tumor size had to be $\geq 1 \mathrm{~cm}$ in the ultrasound in GeparQuattro and GeparQuinto, $\geq 3 \mathrm{~cm}$ in AGO1 and $\geq 2 \mathrm{~cm}$ in all other trials. ER/PR status was defined as positive if at least $10 \%$ of cells stained positive. The NACT of each trial contained an anthracycline- and taxane-based chemotherapy backbone. In GeparQuattro and Techno, HER2+ patients received one year of trastuzumab. In GeparQuinto, HER2+ patients received trastuzumab and lapatinib versus bevacizumab if HER2-, with non-responders after four cycles of epirubicin and cyclophosphamide being randomized to a treatment with paclitaxel with or without everolimus. We included all patients with minimum one cycle of preoperative medical treatment in this analysis. Patients with estrogen receptor (ER) and/or progesterone receptor (PR) positive breast cancer had to receive adjuvant endocrine treatment for at least 5 years according to German guidelines [18]. Also, adjuvant radiation therapy had to be performed accordingly (e.g. whole breast radiation therapy after breast conserving surgery or radiation of thoracic wall after mastectomy for clinical and/or histological stages T3, T4, N2, N3) [18].

\section{Objectives and endpoints}

The primary aim of this combined analysis was to identify elderly patients likely to profit from NACT by evaluating $\mathrm{pCR}$ rates for women $>65 \mathrm{y}$ compared to younger patients (age groups: $<40 \mathrm{y} ; 40-50 \mathrm{y} ; 51-65 \mathrm{y}$ ), overall and in different biological subgroups defined by hormone receptor (HR) and HER2-status. Pathological complete response was defined as ypT0 ypN0 (no invasive and no non-invasive residuals in the breast and nodes) [5].

Further aims were to assess the effect of age $>65 \mathrm{y}$ on DFS, LRFS, DDFS and OS, overall, in the pCR- and non-pCR group and in biological subgroups compared to younger patients.

\section{Statistics}

Individual data at surgery and in follow-up was extracted for this combined analysis from all participating 8949 patients. As defined in the protocols, patients with missing data on histopathological response, e.g. because of having no surgery, were counted as having no response. Baseline parameters were correlated with pCR using twosided Pearson Chi square test or Fisher's exact test. Survival was calculated by the date of randomization to event or last follow-up and plotted as Kaplan-Meier curves with log-rank $p$-values. Odds ratios and hazard ratios, $95 \%$ confidence intervals (CI) and corresponding p-values between categorized score values were calculated using logistic regression and Cox regression analysis. No adjustment was made for performing multiple tests, and all of the probability values were two sided with an alpha of 0.05 for statistical significance. SPSS 20.0 was used to perform analyses. 


\section{RESULTS}

From the total of 8949 patients included in the analysis $566(6.3 \%)$ were older than 65 years. Median age of all patients was 49 years (21-80 y). Older patients had a significantly higher body mass index (BMI) compared to younger patients. Information about ER, PR, HER2 was available in $6763(75.6 \%)$ patients. Table 1 describes the baseline characteristics of patients, tumor and surgery.

Women older than 65 years had significant larger tumors stage T4a-d, lymph node involvement (LN 1-9) compared to the other age groups and lobular invasive tumors compared to patients less than 50 years. Histologically, the majority of patients $>65$ years had G2 and estrogen receptor positive tumors. Compared to the young women ( $<40$ years) there is no difference for PR. HER2-status was not statistically different between the age groups. There were more HR+/HER2tumors and fewer HR+/HER2+ tumors in the elderly group compared to all other patient groups. Women $>65$ years had less triple negative tumors than women $<40$ years. The rate of HR-/HER2+ tumors was between $10.3 \%$ and $12.5 \%$ in all groups. HR-/HER2+ tumors were the most rarely found subtype in our cohort with $11.4 \%$.

\section{pCR analyses}

We found an age dependent rate of pCR, which showed that $\mathrm{pCR}$ is lowest for elderly $>65$ patients $(11.7 \%)$ and is higher with decreasing age. The highest $\mathrm{pCR}$ rate is found in the group of $<40$ year old women (20.9\%) (Table 3).

In the HR+/HER - group women $>65$ years had lowest $\mathrm{pCR}$ rates of all subgroups (3.1\%).

Within the two HER2+ subgroups, no significant age related differences were found.

For TNBC, the pCR rate was also significantly the lowest in the subgroup of women $>65$ years.

The multivariable logistic regression analysis of clinical parameters showed that young age, clinical stage T4a-d, invasive ductal cancer and G3 breast cancer are predictive for high $\mathrm{pCR}$. The multivariate analyses of molecular subgroups also showed that age $>65$ years is a predictor of significant lower pCR in TNBC, HR+/HER2-, $\mathrm{G} 3$ and $\mathrm{N}+$ breast cancers.

\section{Survival analyses}

During a median follow up period of 62.5 (62.0-63.0) months, 717 (8.0\%) local-recurrences, 1799 distant events (20.1\%), and 1336 (14.9\%) deaths were observed.

Women $>65$ years had a significant better LRFS than women between $40-50$ years and women $<40$ years (Table 2; Figure 1).

For the overall survival, we found a significantly worse outcome for patients $>65$ years compared to women age 5165 years and women $40-50$ years. The DDFS and DFS which exclude death from other factors than cancer - showed no statistical difference (Figure 2; Figure 3; Table 2). Despite not showing statistical significance, women $>65$ years had a worse DFS compared to women 40-50 y and 51-65 years, but not compared to women $<40$ years (Figure 3 ).

Within the breast cancer subtypes, a significant better DDFS was found for patients between 40-50 years old compared to the elderly $>65$ in the HR+/HER2group. In the HR-/HER2+ subgroup the DDFS for the same group of age was significantly worse compared to the elderly $>65$ years. (Table 2 ).

A statistical significance for OS was evaluated for the HR+/HER2 - subgroup, where the elderly $>65$ had a survival disadvantage compared to women age 51-65 years and women $40-50$ years (Table 2). This survival disadvantage (OS) for women $>65$ years is not sustained when a pCR is achieved (Figures 4 and 5).

pCR is strongly associated with better OS in all age groups (Figure 6). There were no significant differences between age $>65$ years and other age groups if $\mathrm{pCR}$ was achieved.

Besides age, pCR, N-status and tumor stage had significant impact on DFS, LRFS, DDFS, and OS. Additionally, the grading had a significant impact on DFS, LRFS and OS but not on DDFS.

After adjustment for known prognostic factors and age, women $>65$ years had a worse OS compared to the age group 40-50 (HR $=0.74$ [95\% CI $0.60-0.91] ; p$ $=0.005)$ and $51-65(\mathrm{HR}=0.73[95 \%$ CI $0.59-0.90] ; p$ $=0.003)$. Elderly women with HR+/HER2 - subtype had a significantly worse OS compared to patients aged 40-50 $(\mathrm{HR}=0.50[95 \% \mathrm{CI} 0.35-0.73] ; p<0.001)$ and 51-65 $(\mathrm{HR}=0.60[95 \%$ CI $0.42-0.86] ; p=0.005)$. No statistically significant difference was found in the other subgroups.

\section{DISCUSSION}

Half of the women with breast cancer in Germany are older than 65 years [2]. This is not only a numerous but also important group in need for treatment - especially as the life expectancy in Germany and western European countries is rising [19]. In our analysis of 8949 patients the percentage of women $>65$ years is only $6.32 \%$. This shows again that elderly are underrepresented in clinical trials [20].

It has to be mentioned critically, that there is no information about Ki-67 activity in this analysis to distinguish Luminal A from Luminal B tumors, which benefit differently from chemotherapy [18]. Another limitation of this study is that we do not have information about residual cancer burden or tumor-infiltrating lymphocytes which are identified as predictors of chemotherapy response in other studies [21, 22]. The analyzed database does not provide information about chemotherapy related toxicity. For every patient, the relation between risk and benefit of an anticancer therapy has to be evaluated before and during treatment. Elderly patients often have more comorbidities and often receive comedication. According to a systematical review [23] there are age related differences in pharmacokinetics of breast cancer treatment as they contain anthracyclines (reduced clearance) and 
Table 1: Baseline characteristics of patients, tumor and surgery

\begin{tabular}{|c|c|c|c|c|c|c|c|c|c|c|c|}
\hline & \multicolumn{2}{|c|}{$\begin{array}{c}<40 y \\
n=1453\end{array}$} & \multicolumn{2}{|c|}{$\begin{array}{l}40-50 y \\
n=3420\end{array}$} & \multicolumn{2}{|c|}{$\begin{array}{l}51-65 y \\
n=3510\end{array}$} & \multicolumn{2}{|c|}{$\begin{array}{c}>65 y \\
n=566\end{array}$} & \multicolumn{2}{|c|}{$\begin{array}{c}\text { all patients } \\
n=8949\end{array}$} & \multirow[t]{2}{*}{$p$ value } \\
\hline & $n$ & Valid \% & $n$ & Valid \% & $n$ & Valid \% & $n$ & Valid \% & $n$ & Valid \% & \\
\hline Tumor stage & & & & & & & & & & & $<0.001$ \\
\hline cT1 & 135 & 9.4 & 283 & 8.3 & 192 & 5.5 & 24 & 4.3 & 634 & 7.1 & \\
\hline cT2 & 984 & 68.3 & 2189 & 64.5 & 2175 & 62.4 & 310 & 55.3 & 5658 & 63.7 & \\
\hline cT3 & 214 & 14.9 & 586 & 17.3 & 567 & 16.3 & 95 & 16.9 & 1462 & 16.5 & \\
\hline cT4a-c & 50 & 3.5 & 181 & 5.3 & 277 & 8.0 & 67 & 11.9 & 575 & 6.5 & \\
\hline cT4d & 57 & 4.0 & 153 & 4.5 & 272 & 7.8 & 65 & 11.6 & 547 & 6.2 & \\
\hline Missing & & & & & & & & & 73 & 0.8 & \\
\hline Nodal status & & & & & & & & & & & 0.031 \\
\hline No & 731 & 51.6 & 1670 & 49.7 & 1649 & 47.9 & 249 & 44.5 & 4299 & 49.0 & \\
\hline $\mathrm{N} 1-3$ & 619 & 43.7 & 1518 & 45.2 & 1578 & 45.8 & 272 & 48.6 & 3987 & 45.4 & \\
\hline $\mathrm{N} 4-9$ & 50 & 3.5 & 131 & 3.9 & 163 & 4.7 & 32 & 5.7 & 376 & 4.3 & \\
\hline $\mathrm{N}>10$ & 18 & 1.3 & 38 & 1.1 & 56 & 1.6 & 7 & 1.3 & 119 & 1.4 & \\
\hline Missing & & & & & & & & & 168 & 1.9 & \\
\hline Histological type & & & & & & & & & & & $<0.001$ \\
\hline Ductal invasive & 1221 & 85.7 & 2721 & 81.5 & 2720 & 79.0 & 439 & 77.6 & 7101 & 81.0 & \\
\hline Lobular invasive & 86 & 6.0 & 400 & 12.0 & 502 & 14.6 & 78 & 13.8 & 1066 & 12.2 & \\
\hline Others & 117 & 8.2 & 217 & 6.5 & 221 & 6.4 & 49 & 8.7 & 604 & 6.9 & \\
\hline Missing & & & & & & & & & 178 & 2.0 & \\
\hline Tumor grade & & & & & & & & & & & $<0.001$ \\
\hline G1 & 42 & 3.1 & 137 & 4.2 & 119 & 3.6 & 17 & 3.1 & 315 & 3.7 & \\
\hline $\mathrm{G} 2$ & 684 & 49.8 & 1812 & 55.6 & 1839 & 55.6 & 322 & 59.1 & 4657 & 54.9 & \\
\hline G3 & 647 & 47.1 & 1312 & 40.2 & 1350 & 40.8 & 206 & 37.8 & 3515 & 41.4 & \\
\hline Missing & & & & & & & & & 462 & 5.2 & \\
\hline ER status & & & & & & & & & & & $<0.001$ \\
\hline Negative & 630 & 45.4 & 1244 & 37.8 & 1206 & 35.8 & 198 & 35.2 & 3278 & 38.1 & \\
\hline Positive & 758 & 54.6 & 2050 & 62.2 & 2160 & 64.2 & 365 & 64.8 & 5333 & 61.9 & \\
\hline Missing & & & & & & & & & 338 & 3.8 & \\
\hline PR status & & & & & & & & & & & $<0.001$ \\
\hline Negative & 700 & 50.5 & 1415 & 43.0 & 1611 & 48.0 & 284 & 50.5 & 4010 & 46.6 & \\
\hline Positive & 687 & 49.5 & 1878 & 57.0 & 1746 & 52.0 & 278 & 49.5 & 4589 & 53.4 & \\
\hline Missing & & & & & & & & & 350 & 3.9 & \\
\hline HER-2 Status & & & & & & & & & & & 0.072 \\
\hline Negative & 829 & 72.1 & 2050 & 74.4 & 1974 & 74.2 & 371 & 78.4 & 5224 & 74.2 & \\
\hline Positive & 320 & 27.9 & 707 & 25.6 & 688 & 25.8 & 102 & 21.6 & 1817 & 25.8 & \\
\hline Missing & & & & & & & & & 1908 & 21.3 & \\
\hline Molecular subtypes & & & & & & & & & & & $<0.001$ \\
\hline $\begin{array}{l}\text { HR positive/ } \\
\text { HER2- }\end{array}$ & 463 & 42.3 & 1309 & 49.2 & 1319 & 51.8 & 256 & 54.9 & 3347 & 49.5 & \\
\hline $\begin{array}{l}\text { HR positive/ } \\
\text { HER2+ }\end{array}$ & 174 & 15.9 & 419 & 15.8 & 358 & 14.1 & 54 & 11.6 & 1005 & 14.9 & \\
\hline $\begin{array}{l}\text { HR negative/ } \\
\text { HER2+ }\end{array}$ & 137 & 12.5 & 275 & 10.3 & 313 & 12.3 & 48 & 10.3 & 773 & 11.4 & \\
\hline TNBC & 320 & 29.3 & 655 & 24.6 & 555 & 21.8 & 108 & 23.2 & 1638 & 24.2 & \\
\hline Missing & & & & & & & & & 2186 & 24.4 & \\
\hline BMI & & & & & & & & & & & $<0.001$ \\
\hline$<18.5$ & 42 & 2.9 & 63 & 1.9 & 30 & 0.9 & 3 & 0.5 & 138 & 1.6 & \\
\hline
\end{tabular}




\begin{tabular}{|c|c|c|c|c|c|c|c|c|c|c|c|}
\hline $18.5-24.9$ & 895 & 62.0 & 1802 & 53.1 & 1377 & 39.7 & 189 & 33.4 & 4263 & 48.0 & \\
\hline $25.0-29.9$ & 325 & 22.5 & 1009 & 29.7 & 1224 & 35.3 & 215 & 38.0 & 2773 & 31.2 & \\
\hline $30.0-39.9$ & 163 & 11.3 & 480 & 14.1 & 784 & 22.6 & 145 & 25.6 & 1572 & 17.7 & \\
\hline$\geq 40$ & 19 & 1.3 & 40 & 1.2 & 55 & 1.6 & 14 & 2.5 & 128 & 1.4 & \\
\hline Missing & & & & & & & & & 75 & 0.8 & \\
\hline Surgery Type & & & & & & & & & & & $<0.001$ \\
\hline $\begin{array}{l}\text { Breast conserving } \\
\text { therapy }\end{array}$ & 992 & 71.9 & 2321 & 70.7 & 2333 & 70.1 & 310 & 58.5 & 5956 & 69.9 & \\
\hline Mastectomy & 387 & 28.1 & 964 & 29.3 & 997 & 29.9 & 220 & 41.5 & 2568 & 30.1 & \\
\hline Missing & & & & & & & & & 425 & 4.7 & \\
\hline
\end{tabular}

" $\chi^{2}$ or Fisher's test.

Table 2: MVA cox regression of survival data

\begin{tabular}{|c|c|c|c|c|c|c|c|c|c|c|c|c|c|c|c|c|}
\hline \multirow[t]{2}{*}{ Age } & \multicolumn{4}{|c|}{ DDFS } & \multicolumn{4}{|c|}{ LRFS } & \multicolumn{4}{|c|}{ DFS } & \multicolumn{4}{|c|}{ OS } \\
\hline & HR & \multicolumn{2}{|c|}{$95 \%$ CI } & $p$ value & HR & \multicolumn{2}{|c|}{$95 \%$ CI } & $p$ value & HR & \multicolumn{2}{|c|}{$95 \% \mathrm{CI}$} & $p$ value & HR & \multicolumn{2}{|c|}{$95 \% \mathrm{CI}$} & $p$ value \\
\hline$>65$ & 1.00 & & & & & & & & & & & & & & & \\
\hline $51-65$ & 0.85 & 0.70 & 1.02 & 0.082 & 1.21 & 0.85 & 1.72 & 0.287 & 0.90 & 0.75 & 1.08 & 0.267 & 0.73 & 0.59 & 0.90 & 0.003 \\
\hline $40-50$ & 0.87 & 0.72 & 1.06 & 0.164 & 1.44 & 1.01 & 2.05 & 0.043 & 0.96 & 0.80 & 1.16 & 0.696 & 0.74 & 0.60 & 0.91 & 0.005 \\
\hline$<40$ & 1.02 & 0.82 & 1.25 & 0.882 & 1.95 & 1.34 & 2.82 & $<0.001$ & 1.16 & 0.95 & 1.41 & 0.153 & 0.86 & 0.68 & 1.09 & 0.202 \\
\hline \multicolumn{17}{|l|}{ pCR } \\
\hline No pCR & 1.00 & & & & & & & & & & & & & & & \\
\hline pCR vs no pCR & 0.38 & 0.32 & 0.45 & $<0.001$ & 0.33 & 0.25 & 0.44 & $<0.001$ & 0.40 & 0.34 & 0.47 & 0.058 & 0.71 & 0.47 & 1.07 & 0.105 \\
\hline
\end{tabular}

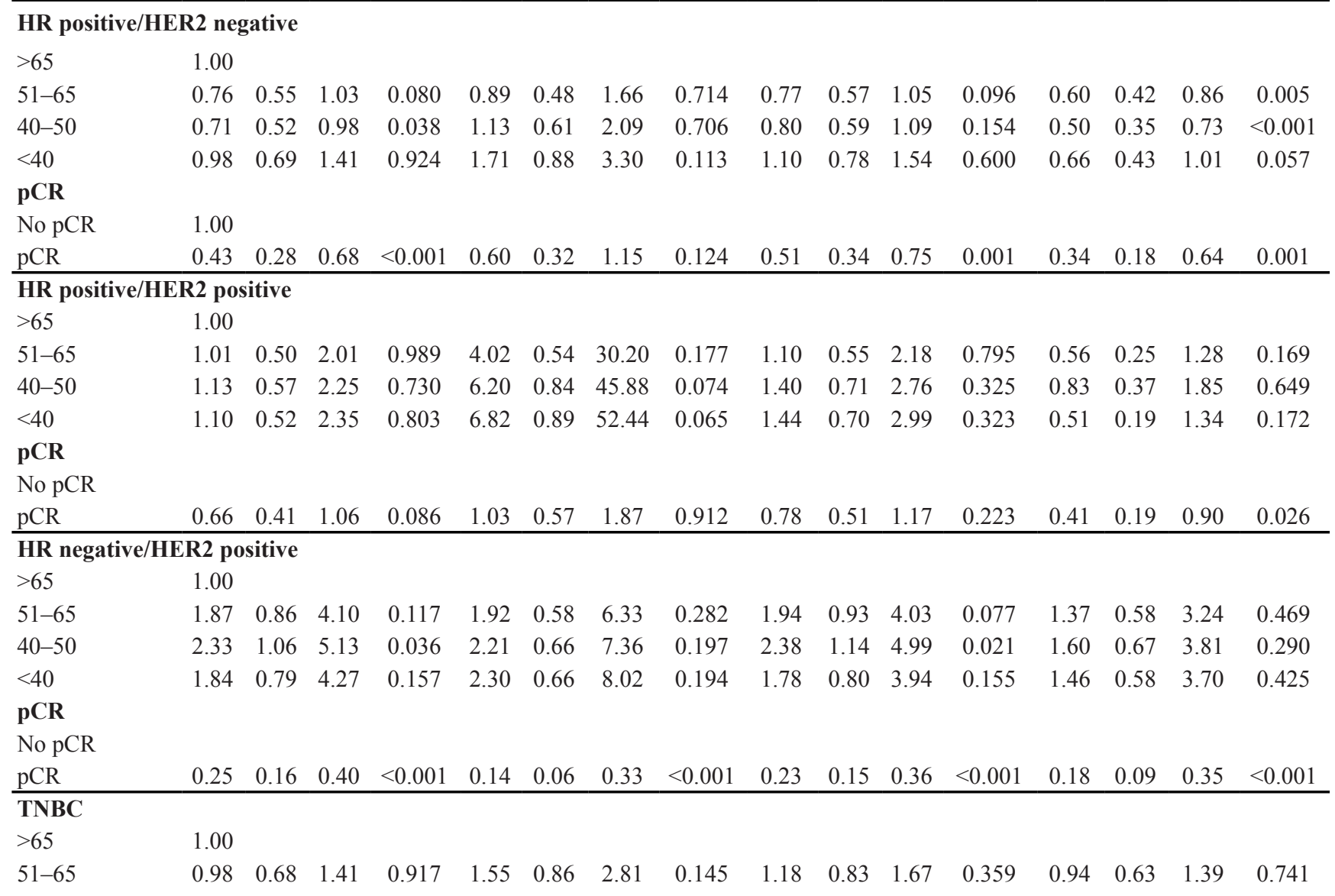




\begin{tabular}{llllllllllllllllll}
$40-50$ & 1.19 & 0.83 & 1.70 & 0.353 & 1.72 & 0.96 & 3.11 & 0.071 & 1.33 & 0.94 & 1.88 & 0.113 & 1.14 & 0.77 & 1.68 & 0.511 \\
$<40$ & 1.01 & 0.68 & 1.51 & 0.952 & 1.76 & 0.94 & 3.29 & 0.075 & 1.22 & 0.83 & 1.78 & 0.309 & 1.05 & 0.68 & 1.61 & 0.826 \\
pCR & & & & & & & & & & & & & & & & \\
No pCR & & & & & & & & & & & & & & & & \\
pCR & 0.18 & 0.13 & 0.25 & $<0.001$ & 0.12 & 0.07 & 0.21 & $<0.001$ & 0.18 & 0.13 & 0.24 & $<0.001$ & 0.17 & 0.12 & 0.24 & $<0.001$ \\
\hline
\end{tabular}

platinum agents (reduced creatinine clearance) - as in all NACT protocols of this study. But it is still questionable whether these differences have any clinical relevance [23]. In general, age cannot be seen as an absolute determinant for the prediction of pharmacokinetics of neoplastic agents, as it does not account for organ function entirely. A more practical approach might be to perform more functional geriatric assessments. A BMI $\geq 30$ (minimum obesity grade 1) in the group of elderly $>65$ was found in $28.1 \%$. Interestingly, in the group of young women $<40$ years it was only found in $12.6 \%$. Obesity is a known risk factor for complications like coronary heart disease, worse impact on chronic heart failure, diabetes type II and therefore also renal insufficiency - known risk factors for survival outcomes and oftentimes limiting factors for the dosage or even reason for discontinuation of anticancer agents.

The analysis also showed that pCR is not only age dependent, but also differs significantly between the biological subtypes of breast cancer. In the triple negative and HR+/HER2- subgroups the pCR rate of the elderly $>65$ years is significantly lower in comparison to all other groups. Again, a continuously increasing pCR rate was found for higher age. Nevertheless, this effect was not found in HR+/HER2+ and HR-/HER2+ cohort. The pCR rate was significantly lower in elderly patients with HR+/HER2- and TNBC breast cancer. On the other hand, $\mathrm{pCR}$ rates in our analysis were not different between elderly and younger patients in the histological subgroups HR+/HER2+ and HR-/HER2+. As HER2+ specific therapies such as trastuzumab are routinely added to chemotherapy this effect may dominate the age dependent absolute effect of chemotherapy. Age might be negated partially by the effectiveness of anti-HER2 treatment, but it was not available for all patients in this analysis (not available in GeparDuo, GeparTrio, AGO 1 and Prepare).

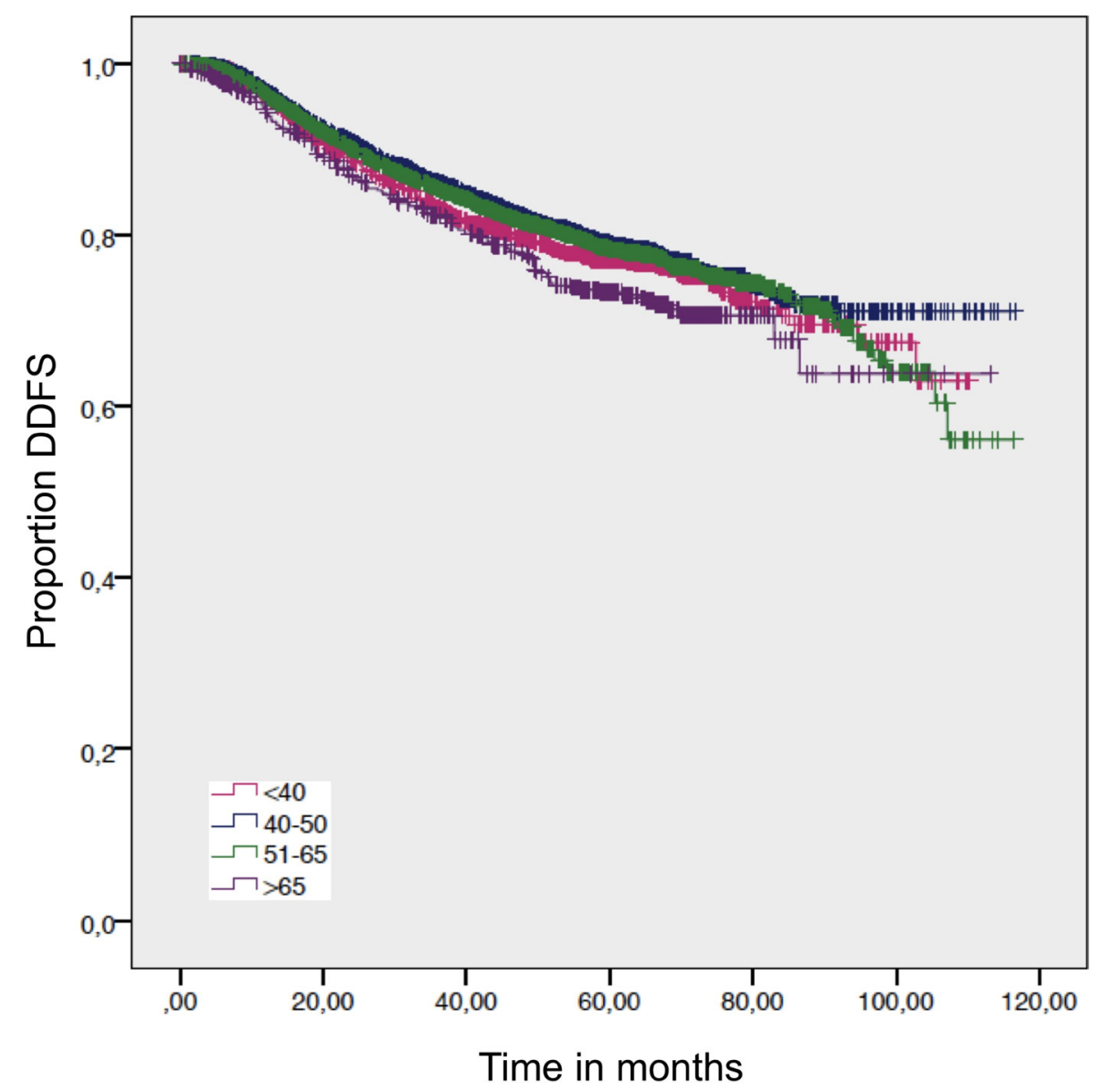

Figure 1: Distant disease free survival by age. Log-rank $p$-value $=0.016$. 


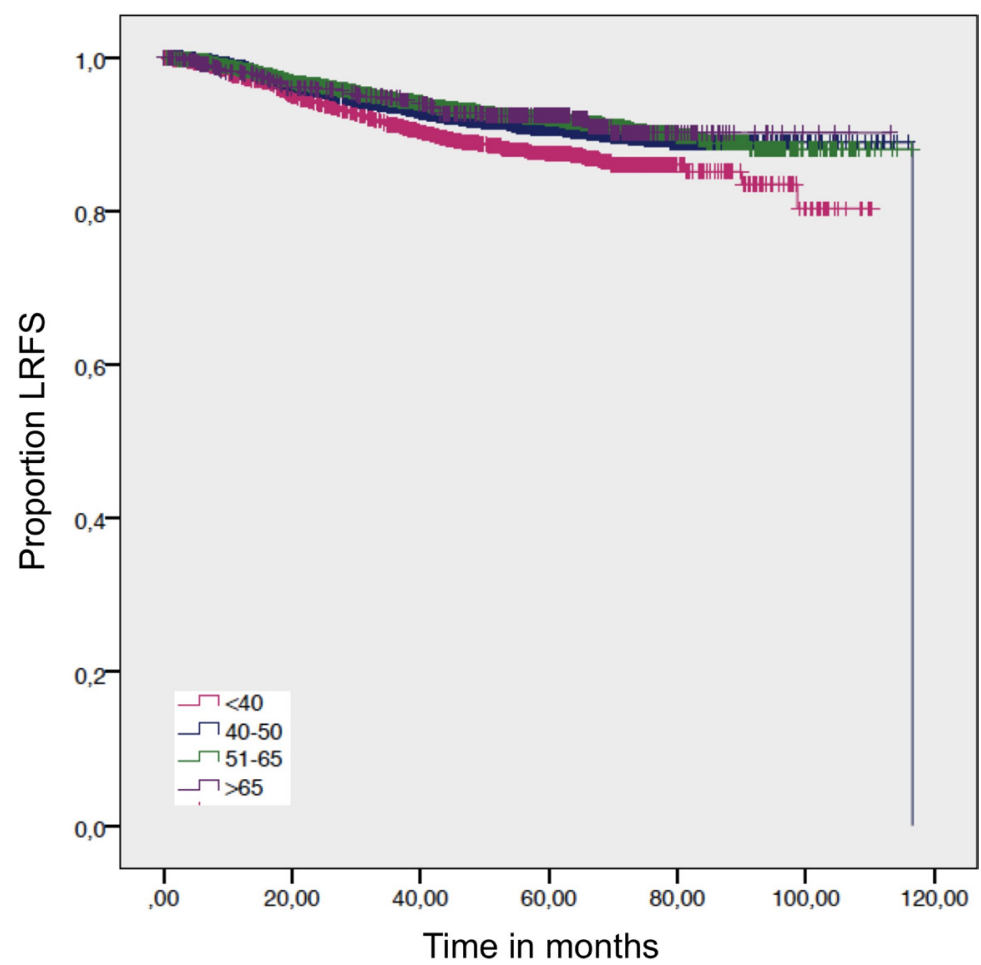

Figure 2: Local-recurrence-free survival by age. Log-rank $p$-value $=0.001$.

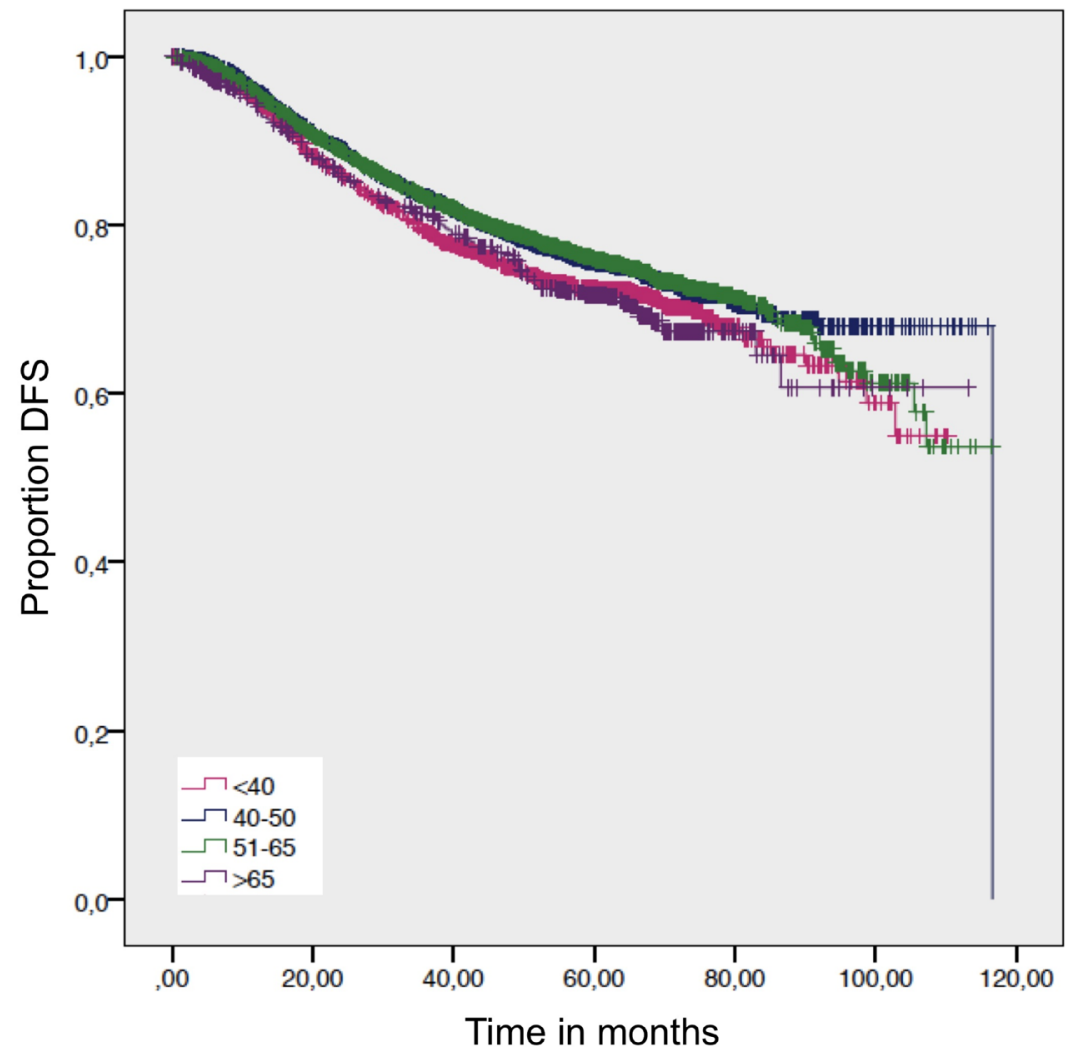

Figure 3: Disease free survival. Log-rank $p$-value $=0.009$. 


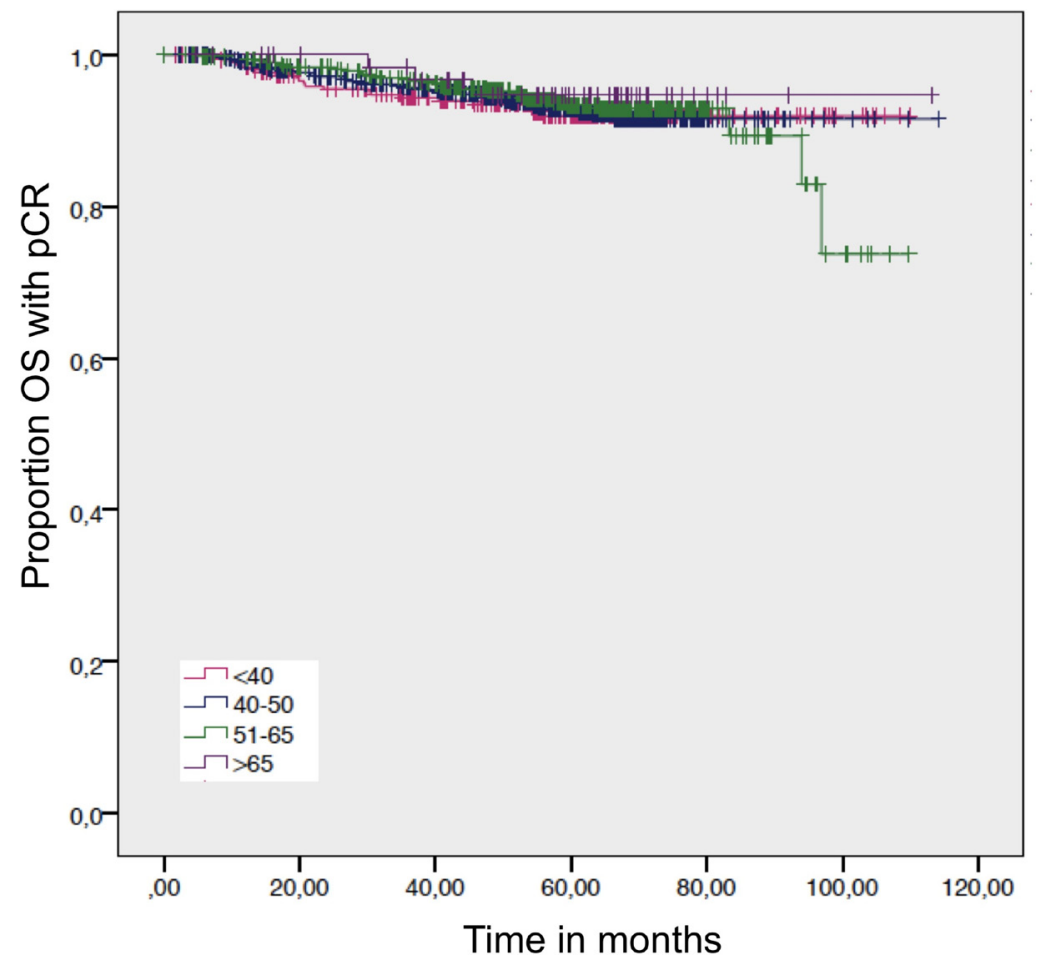

Figure 4: Overall survival in patients with a pathological complete response by age. $\log$-rank $p$-value $=0.899$.

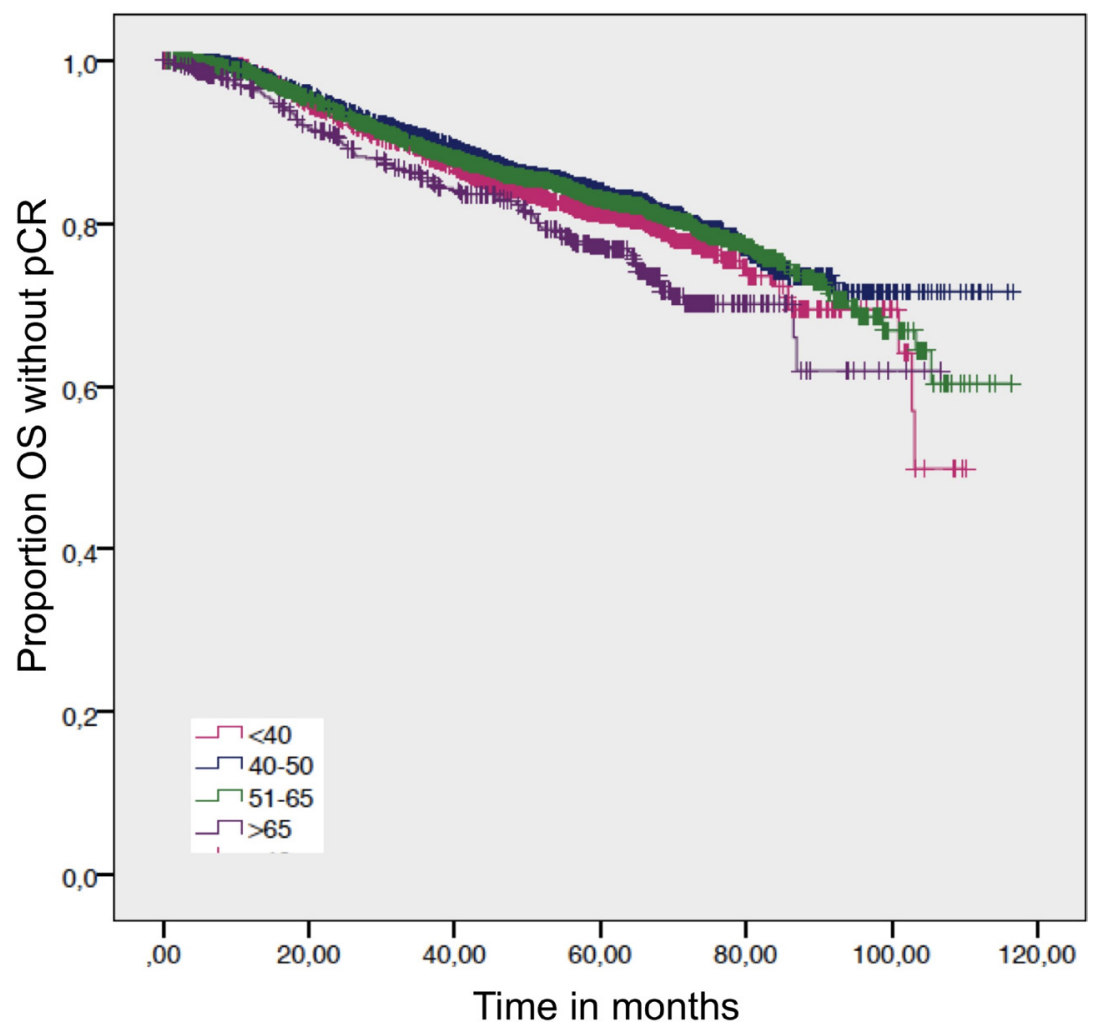

Figure 5: Overall survival in patients without a pathological complete response by age. $\log$-rank $p$-value $=0.001$. 
In addition, DFS, LRFS, DDFS and OS are significantly longer in the group of patients $>65$ years, if pCR is achieved in the TNBC subtype. For the other subtypes there is no significant difference found. Missing systemic therapy for TNBC besides chemotherapy and in contrast effective systemic therapy for HR+ and HER2+ tumors may be an explanation. These findings support the necessity for the more frequent consideration of neoadjuvant antihormonal treatment for these patients, and is under further investigation in other multicenter trials [24].

The pCR rates do not necessarily correlate with shortened OS in all histological subtypes, as other studies already showed $[25,26]$.

An explanation for lower pCR may be that the tumors of the elderly, as shown in this population, contain more G2 differentiated tumors and less G3 than all other groups, and also have the highest rate of invasive lobular cancers. These characteristics are unfavorable for pCR, as predictors for achieving pCR rather are G3- and invasive ductal cacinomas $[25,27]$.
The overall survival of elderly women in our study was worse compared to younger patients. For patients $>65$ years all prognostic outcomes (DFS, DDFS, LRFS, OS) were associated with immunohistological subtype as shown in other recent publications [28]. The breast cancer related prognosis is not related to a specific age, but it depends on individual tumor associated factors like specific gene expression [29]. Higher prevalence of HR-positive tumors is age related [29]. In our study we only have OS data but no breast cancer specific survival data. J. Patnaik et al. showed that comorbidity is associated with decreased OS and increased mortality. Furthermore it was shown that patients $>65$ years with comorbid condition and stage I tumor had similar or poorer OS compared to patients who had no comorbid condition and stage II tumor [30].

In conclusion, this study supports the data showing the unfavorable impact of age on pCR, especially for TNBC. Nevertheless, it shows the realistic chance of pCR using NACT. Especially pCR rates of HER2+ patients were as high - and for HR+/HER2+ even higher - than of younger patients. Secondly, elderly patients with non-

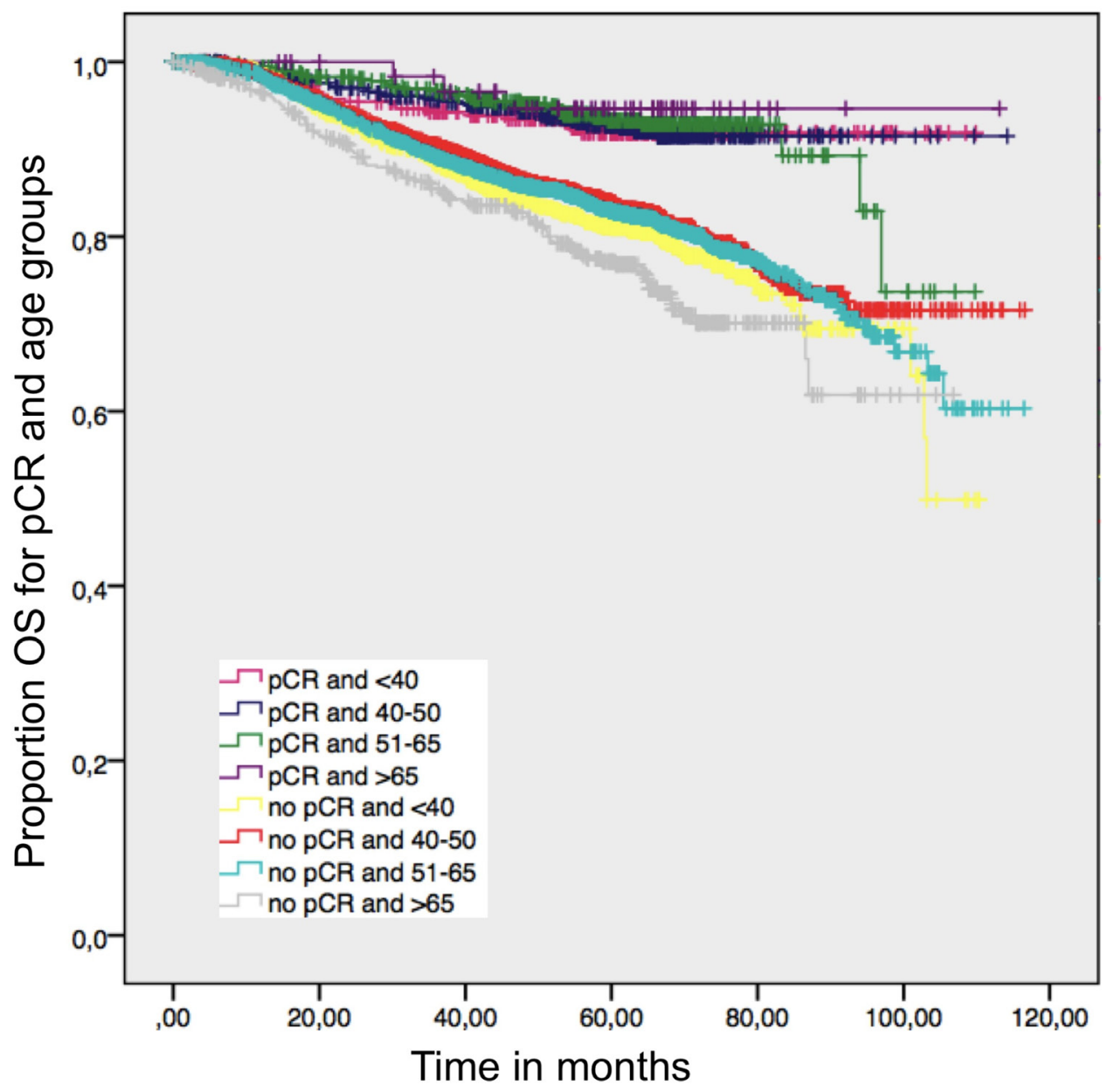

Figure 6: Overall survival in patients with and without a pathological complete response by age; log-rank $p$ value $=$ 0.001 . 
Table 3: pCR

\begin{tabular}{|c|c|c|c|}
\hline Age & pCR (\%) & $\begin{array}{c}\text { Logistic regression" } \\
\text { Odds Ratio (95\% CI) }\end{array}$ & $p$-value \\
\hline \multicolumn{4}{|l|}{ overall } \\
\hline$>65$ & 11.7 & 1.00 & \\
\hline $51-65$ & 14.1 & $1.32(0.99-1.77)$ & 0.063 \\
\hline $40-50$ & 17.3 & $1.57(1.18-2.10)$ & 0.002 \\
\hline$<40$ & 20.9 & $1.84(1.35-2.50)$ & $<0.001$ \\
\hline \multicolumn{4}{|c|}{ HR+/HER2- } \\
\hline$>65$ & 3.1 & 1.00 & \\
\hline $51-65$ & 6.2 & $2.06(0.98-4.32)$ & 0.058 \\
\hline $40-50$ & 8.3 & $2.70(1.29-5.65)$ & 0.008 \\
\hline$<40$ & 11.0 & $3.45(1.59-7.46)$ & 0.002 \\
\hline \multicolumn{4}{|c|}{ HR+/HER2+ } \\
\hline$>65$ & 20.4 & 1.00 & \\
\hline $51-65$ & 19.0 & $0.90(0.40-1.95)$ & 0.786 \\
\hline $40-50$ & 18.4 & $0.87(0.40-1.88)$ & 0.716 \\
\hline$<40$ & 19.0 & $0.88(0.38-2.03)$ & 0.756 \\
\hline \multicolumn{4}{|c|}{ HR-/HER2+ } \\
\hline$>65$ & 33.3 & 1.00 & \\
\hline $51-65$ & 34.8 & $1.13(0.56-2.25)$ & 0.737 \\
\hline $40-50$ & 29.1 & $0.81(0.40-1.65)$ & 0.562 \\
\hline$<40$ & 29.2 & $0.94(0.44-2.02)$ & 0.877 \\
\hline \multicolumn{4}{|l|}{ TNBC } \\
\hline$>65$ & 19.4 & 1.00 & \\
\hline $51-65$ & 26.5 & $1.50(0.88-2.56)$ & 0.136 \\
\hline $40-50$ & 35.6 & $2.07(1.23-3.50)$ & 0.007 \\
\hline$<40$ & 38.8 & $2.21(1.27-3.84)$ & 0.005 \\
\hline
\end{tabular}

*adjusted for study, tumor and nodal stage, histotype, grading.

TNBC have a comparably good prognosis regarding OS, even if no pCR is achieved.

\section{Abbreviations}

BMI: body mass index; CI: confidence interval; DDFS : distant disease free survival; DFS: disease free survival; ER: estrogen receptor; LRFS: local-recurrencefree survival; MVA: multivariate analysis; NACT: neoadjuvant chemotherapy; OS: overall survival; pCR: pathological complete response; PR: progesterone receptor; TNBC: triple negative breast candor.

\section{Author contributions}

Conception of the work: $\mathrm{G}$ von Waldenfels, JU Blohmer, S Loibl; Data collection: C Denkert, C Hanusch, J Huober, C Jackisch, S Kümmel, S Loibl, G von Minckwitz, A Schneeweiss, M Untch, K Rhiem, PA Fasching, JU
Blohmer; Data analysis and interpretation: B Lederer, G von Waldenfels, J Furlanetto, A Machleidt; Drafting the article G von Waldenfels, JU Blohmer; Critical revision of the article: G von Waldenfels, S Loibl, J Furlanetto, A Machleidt, B Lederer, C Denkert, C Hanusch, J Huober, C Jackisch, S Kümmel, S Loibl, G von Minckwitz, A Schneeweiss, M Untch, K Rhiem, PA Fasching, JU Blohmer.

\section{ACKNOWLEDGMENTS}

We would like to thank all patients, investigators and study personnel who supported the trials and the German Breast Group for the support.

\section{CONFLICTS OF INTEREST}

Claus Hanusch: Speaker/Advisory Board: Roche, Amgen, Novartis, Cellgene. Sherko Kümmel: Honoraria: Roche, Amgen, Novartis, Teva, Daiichi-Sankyo, Celgene, 
Pfizer; Research Funding: Roche; Travel, Accomodations, Expenses: Roche, Teva. Peter A. Fasching: Honoraria: Amgen, Novartis, Pfizer, Celgene, Roche.

\section{FUNDING}

No grant support.

\section{REFERENCES}

1. Biganzoli L, Wildiers H, Oakman C, Marotti L, Loibl S, Kunkler I, Reed M, Ciatto S, Voogd AC, Brain E, Cutuli B, Terret C, Gosney M, et al. Management of elderly patients with breast cancer: Updated recommendations of the International Society of Geriatric Oncology (SIOG) and European Society of Breast Cancer Specialists (EUSOMA). Lancet Oncol. 2012; 13:e148-60. https://doi.org/10.1016/ S1470-2045(11)70383-7.

2. Barinoff J, Traut A, Bauerschlag D, Bischoff J, Herr D, Lübbe K, Lück HJ, Maass N, Mundhenke C, Schmidt M, Schwedler K, Thill M, Steffen J, et al. Chemotherapy for 70-Year-old women with breast cancer in Germany: A survey by the German breast group. Geburtshilfe Frauenheilkd. 2013; 73:433-9. https://doi. org/10.1055/s-0032-1328612.

3. Hutchins LF, Unger JM, Crowley JJ, Coltman CA, Albain KS. Underrepresentation of patients 65 years of age or older in cancer-treatment trials. N Engl J Med. 1999; 341:2061-7. https://doi.org/10.1056/NEJM199912303412706.

4. Kumar A, Soares HP, Balducci L, Djulbegovic B, and National Cancer Institute. Treatment tolerance and efficacy in geriatric oncology: a systematic review of phase III randomized trials conducted by five National Cancer Institute-sponsored cooperative groups. J Clin Oncol. 2007; 25:1272-76. https://doi.org/10.1200/JCO.2006.09.2759.

5. Von Minckwitz G, Untch M, Blohmer JU, Costa SD, Eidtmann H, Fasching PA, Gerber B, Eiermann W, Hilfrich J, Huober J, Jackisch C, Kaufmann M, Konecny GE, et al. Definition and impact of pathologic complete response on prognosis after neoadjuvant chemotherapy in various intrinsic breast cancer subtypes. J Clin Oncol. 2012; 30:1796-804. https://doi.org/10.1200/JCO.2011.38.8595.

6. Loibl S, Jackisch C, Lederer B, Untch M, Paepke S, Kümmel S, Schneeweiss A, Huober J, Hilfrich J, Hanusch C, Gerber B, Eidtmann H, Denkert C, et al. Outcome after neoadjuvant chemotherapy in young breast cancer patients: a pooled analysis of individual patient data from eight prospectively randomized controlled trials. Breast Cancer Res Treat. 2015; 152:377-87. https://doi. org/10.1007/s10549-015-3479-z.

7. Loibl S, von Minckwitz G, Untch M, Denkert C, and German Breast Group. Predictive factors for response to neoadjuvant therapy in breast cancer. Oncol Res Treat. 2014; 37:563-68. https://doi.org/10.1159/000367643.
8. Halfter K, Ditsch N, Kolberg HC, Fischer H, Hauzenberger T, von Koch FE, Bauerfeind I, von Minckwitz G, Funke I, Crispin A, Mayer B. Prospective cohort study using the breast cancer spheroid model as a predictor for response to neoadjuvant therapy - the SpheroNEO study. BMC Cancer. 2015; 15: 519. https://doi.org/10.1186/ s12885-015-1491-7.

9. von Minckwitz G, Raab G, Caputo A, Schütte M, Hilfrich J, Blohmer JU, Gerber B, Costa SD, Merkle E, Eidtmann H, Lampe D, Jackisch C, du Bois A, Kaufmann M. Doxorubicin with cyclophosphamide followed by docetaxel every 21 days compared with doxorubicin and docetaxel every 14 days as preoperative treatment in operable breast cancer: the GEPARDUO study of the German Breast Group. J Clin Oncol. 2005; 23:2676-85.

10. von Minckwitz G, Blohmer JU, Raab G, Löhr A, Gerber B, Heinrich G, Eidtmann H, Kaufmann M, Hilfrich J, Jackisch C, Zuna I, Costa SD, and German Breast Group. In vivo chemosensitivity-adapted preoperative chemotherapy in patients with early-stage breast cancer: the GEPARTRIO pilot study. Ann Oncol. 2005; 16:56-63. https://doi. org/10.1093/annonc/mdi001.

11. von Minckwitz G, Kümmel S, Vogel P, Hanusch $C$, Eidtmann H, Hilfrich J, Gerber B, Huober J, Costa SD, Jackisch C, Loibl S, Mehta K, Kaufmann M, and German Breast Group. Intensified neoadjuvant chemotherapy in early-responding breast cancer: Phase III randomized GeparTrio study. J Natl Cancer Inst. 2008; 100:552-62. https://doi.org/10.1093/jnci/djn089.

12. Untch M, Rezai M, Loibl S, Fasching PA, Huober J, Tesch H, Bauerfeind I, Hilfrich J, Eidtmann H, Gerber B, Hanusch C, Küehn T, Du Bois A, et al. Neoadjuvant treatment with trastuzumab in HER2-positive breast cancer: Results from the GeparQuattro study. J Clin Oncol. 2010; 28:2024-31. https://doi.org/10.1200/JCO.2009.23.8451.

13. Untch M, Möebus V, Kuhn W, Muck BR, Thomssen C, Bauerfeind I, Harbeck N, Werner C, Lebeau A, Schneeweiss A, Kahlert S, Von Koch F, Petry KU, et al. Intensive dosedense compared with conventionally scheduled preoperative chemotherapy for high-risk primary breast cancer. J Clin Oncol. 2009; 27:2938-45. https://doi.org/10.1200/ JCO.2008.20.3133.

14. Untch M, Fasching PA, Konecny GE, von Koch F, Conrad U, Fett W, Kurzeder C, Lück HJ, Stickeler E, Urbaczyk H, Liedtke B, Salat C, Harbeck N, et al, and Arbeitsgemeinschaft Gynäkologische Onkologie PREPARE investigators. PREPARE trial: a randomized phase III trial comparing preoperative, dose-dense, dose-intensified chemotherapy with epirubicin, paclitaxel and CMF versus a standard-dosed epirubicin/cyclophosphamide followed by paclitaxel \pm darbepoetin alfa in primary breast cancerresults at the time of surgery. Ann Oncol. 2011; 22:1988-98.

15. Untch M, Fasching PA, Konecny GE, Hasmüller S, Lebeau A, Kreienberg R, Camara O, Müller V, du Bois A, 
Kühn T. Pathologic complete response after neoadjuvant chemotherapy plus trastuzumab predicts favorable survival in human epidermal growth factor receptor 2overexpressing breast cancer: Results from the TECHNO trial of the AGO and GBG study groups. J Clin Oncol. American Society of Clinical Oncology; 2011; 29:3351-7.

16. von Minckwitz G, Eidtmann H, Rezai M, Fasching PA, Tesch H, Eggemann H, Schrader I, Kittel K, Hanusch C, Kreienberg R, Solbach C, Gerber B, Jackisch C, et al, and German Breast Group, and Arbeitsgemeinschaft Gynäkologische Onkologie-Breast Study Groups. Neoadjuvant chemotherapy and bevacizumab for HER2negative b reast cancer. N Engl J Med. 2012; 366:299-309. https://doi.org/10.1056/NEJMoa1111065.

17. Fontanella C, Lederer B, Gade S, Vanoppen M, Blohmer JU, Costa SD, Denkert C, Eidtmann H, Gerber B, Hanusch C, Hilfrich J, Huober J, Schneeweiss A, et al. Impact of body mass index on neoadjuvant treatment outcome: a pooled analysis of eight prospective neoadjuvant breast cancer trials. Breast Cancer Res Treat. 2015; 150:127-39. https://doi.org/10.1007/s10549-015-3287-5.

18. Diagnosis and treatment of patients with primary and metastatic breast cancer. [cited 2017 Jan 7]. Available 2017 Jan 7, from http:/www.ago-online.de/fileadmin/downloads/ leitlinien/mamma/march2012/14_2012E_Breast_Cancer_ Specific_Situations.pdf.

19. Schneider M. Gesundheit für ein Deutschland. Health Policy. 1991; 19:81-82. https://doi. org/10.1016/0168-8510(91)90076-A.

20. Sautter-Bihl ML, Souchon R, Gerber B. Adjuvant therapy for women over age 65 with breast cancer. Dtsch Arztebl Int. 2011; 108:365-71. https://doi.org/10.3238/ arztebl.2011.0365.

21. Denkert C, von Minckwitz G, Brase JC, Sinn BV, Gade S, Kronenwett R, Pfitzner BM, Salat C, Loi S, Schmitt WD, Schem C, Fisch K, Darb-Esfahani S, et al. Tumorinfiltrating lymphocytes and response to neoadjuvant chemotherapy with or without carboplatin in human epidermal growth factor receptor 2-positive and triplenegative primary breast cancers. J Clin Oncol. 2015; 33:983-91. https://doi.org/10.1200/JCO.2014.58.1967.

22. Symmans WF, Peintinger F, Hatzis C, Rajan R, Kuerer H, Valero V, Assad L, Poniecka A, Hennessy B, Green M, Buzdar AU, Singletary SE, Hortobagyi GN, et al. Measurement of residual breast cancer burden to predict survival after neoadjuvant chemotherapy. J Clin Oncol. 2007; 25:4414-22. https://doi.org/10.1200/ JCO.2007.10.6823.
23. Crombag MR, Joerger M, Thürlimann B, Schellens JH, Beijnen JH, Huitema AD. Pharmacokinetics of selected anticancer drugs in elderly cancer patients: Focus on breast cancer. Cancers (Basel). 2016; 8:1-22. https://doi. org/10.3390/cancers 8010006 .

24. Nitz U, Gluz O, Schumann R, Hofmann D, Kates R, Kuemmel S, Braun M, Schumacher C, Nuding B, Aktas B, Forstbauer H, Maass N, Rezai M, et al. ADAPT - Adjuvant Dynamic marker-Adjusted Personalized Therapy trial optimizing risk assessment and therapy response prediction in early breast cancer. Cancer Res. 2015; 75:OT3-2-04. https://doi.org/10.1158/1538-7445.SABCS14-OT3-2-04.

25. Cristofanilli M, Gonzalez-Angulo A, Sneige N, Kau SW, Broglio K, Theriault RL, Valero V, Buzdar AU, Kuerer H, Buchholz TA, Hortobagyi GN. Invasive lobular carcinoma classic type: response to primary chemotherapy and survival outcomes. J Clin Oncol. 2005; 23:41-8. https:// doi.org/10.1200/JCO.2005.03.111.

26. Cortazar P, Zhang L, Untch M, Mehta K, Costantino JP, Wolmark N, Bonnefoi H, Cameron D, Gianni L, Valagussa P, Swain SM, Prowell T, Loibl S, et al. Pathological complete response and long-term clinical benefit in breast cancer: The CTNeoBC pooled analysis. Lancet. 2014; 384:164-72. https://doi.org/10.1016/S0140-6736(13)62422-8.

27. Cocquyt VF, Blondeel PN, Depypere HT, Praet MM, Schelfhout VR, Silva OE, Hurley J, Serreyn RF, Daems KK, Van Belle SJP. Different responses to preoperative chemotherapy for invasive lobular and invasive ductal breast carcinoma. Eur J Surg Oncol. 2003; 29:361-7. https://doi.org/10.1053/ejso.2002.1404.

28. Engels CC, Kiderlen M, Bastiaannet E, Mooyaart AL, van Vlierberghe R, Smit VT, Kuppen PJ, van de Velde CJ, Liefers GJ. The clinical prognostic value of molecular intrinsic tumor subtypes in older breast cancer patients: A FOCUS study analysis. Mol Oncol. 2016; 10:594-600. https://doi.org/10.1016/j.molonc.2015.11.002.

29. Swain SM, Nunes R, Yoshizawa C, Rothney M, Sing AP. Quantitative Gene Expression by Recurrence Score in ER-Positive Breast Cancer, by Age. Adv Ther. 2015; 32:1222-36. https://doi.org/10.1007/s12325-015-0268-3.

30. Patnaik JL, Byers T, Diguiseppi C, Denberg TD, Dabelea D. The influence of comorbidities on overall survival among older women diagnosed with breast cancer. J Natl Cancer Inst. 2011; 103:1101-11. https://doi.org/10.1093/jnci/djr188. 